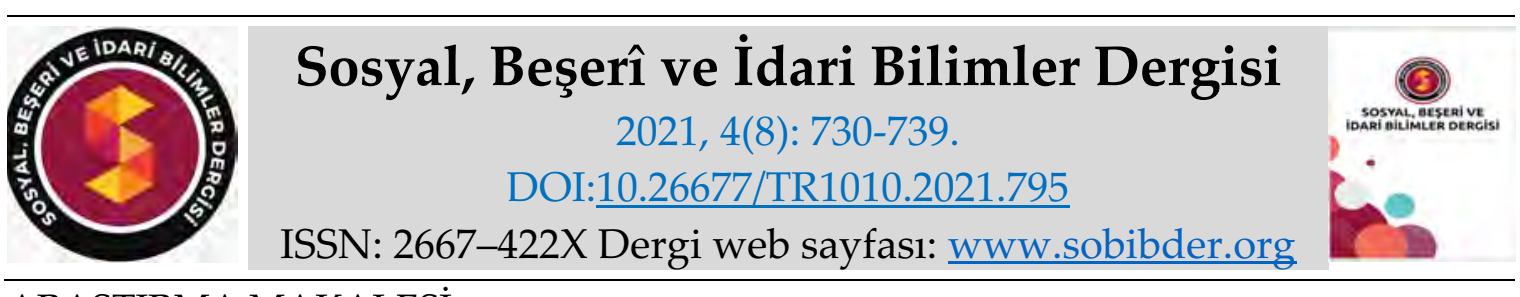

ARASTIRMA MAKALESI

\title{
12- 14 Yaşlarında Olan Ortaokul Öğrencileri İçin Öz-Duyarlık Ölçeğinin Geçerlik ve Güvenirlik Çalışması
}

Uzm. Psk. Filiz ERIŞEN, İzmir Fevzipaşa Ortaokulu, Milli Eğitim Bakanlığı, İzmir, e-posta: filizerisen@gmail.com ORCID: https://orcid.org/0000-0001-6978-119X

Doç. Dr. Füsun GÖKKAYA, Uluslararası Kıbrıs Üniversitesi, Fen-Edebiyat Fakültesi, Kuzey Kıbrıs Türk Cumhuriyeti, e-posta: fusungokkaya@hotmail.com ORCID: https://orcid.org/0000-0002-9392-0724

Arş. Gör. Fatih YURDALAN, Uluslararası Kıbrıs Üniversitesi, Fen-Edebiyat Fakültesi, Kuzey Kıbrıs Türk Cumhuriyeti, e-posta: yurdalanfatih8@gmail.com

ORCID: https://orcid.org/0000-0002-0498-2342

Öz

Öz-Duyarlık Ölçeğinin geçerlik ve güvenirlik çalışmaları ilgili literatür incelendiğinde, orijinali üniversite öğrencileri için geliştirilmiş olan ve bazı araştırmacıların lise düzeyinde ergenlere uyguladığı Öz Duyarlık Ölçeğinin ortaokul öğrencileri (12-14 yaş grubu) ile yapılan bir çalışmasına rastlanmamıştır. Bu kapsamda Öz-duyarlık ölçeğinin, ortaokul öğrencileri için uygunluğunu test etmek amacıyla geçerlik ve güvenirlik analizleri yapılmıştır. Örneklem, 12-14 yaş aralığında olan $339 \mathrm{kız}$ ve 285 erkek toplam 624 ortaokul öğrencisinden oluşmaktadır. Veri toplama aracı olarak Neff (2003a) tarafından geliştirilen Türkçe'ye uyarlama çalışması Akın, Akın ve Abacı (2007) tarafından yapılan Öz-Duyarlık Ölçeği kullanılmıştır. Öz-Duyarlık Ölçeğinin ortaokul öğrencileri için geçerli ve güvenilir bir ölçme aracı olduğu sonucuna ulaşılmıştır. Elde edilen uyum indeksi değerlerinin kabul edilebilir sınırlar içinde olduğu ve bu nedenle modelin iyi uyum gösterdiği görülmektedir. Araştırma sonucunda test tekrar test güvenirliği .76 ve iç tutarlılık katsayısı .89 olarak hesaplanmıştır. Öz-Duyarlılık Ölçeğinin ortaokul öğrencileri için geçerli ve güvenilir bir yapıda olduğu saptanmıştır.

Anahtar Kelimeler: Ortaokul Öğrencileri, Öz-Duyarlık, Geçerlik, Güvenirlik.

Makale Gönderme Tarihi: 30.04.2021

Makale Kabul Tarihi: 01.08.2021

\section{Önerilen Atıf:}

Erişen, E., Gökkaya, F. ve Yurdalan, F. (2021). 12- 14 Yaşlarında Olan Ortaokul Öğrencileri İçin Öz-Duyarlık Ölçeğinin Geçerlik ve Güvenirlik Çalışması, Sosyal, Beşeri ve İdari Bilimler Dergisi, 4(8): 730-739.

(c) 2021 Sosyal, Beşerî ve İdari Bilimler Dergisi. 


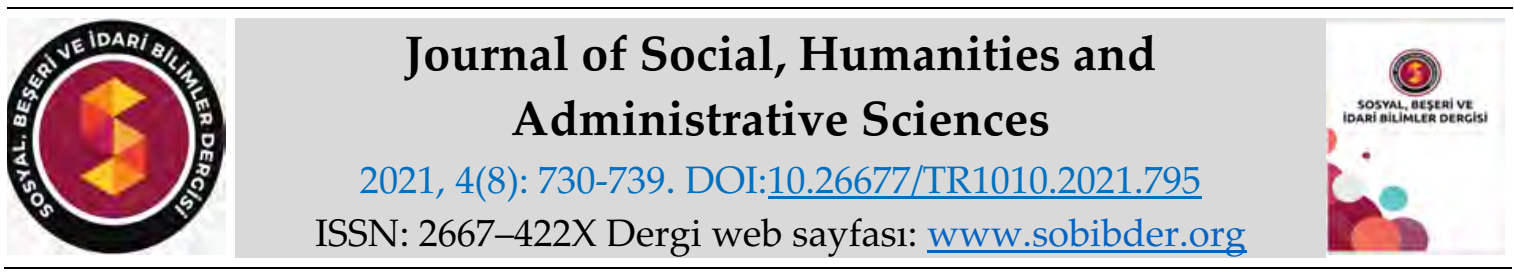

RESEARCH PAPER

\title{
Validity and Reliability Study of The Self-Compassion Scale for Secondary School Students Aged 12- 14 Years
}

Psychologist Filiz ERIŞEN, İzmir Fevzipaşa Secondary School, Ministry of National Education, İzmir, e-mail: filizerisen@gmail.com

ORCID: https://orcid.org/0000-0001-6978-119X

Associate Prof. Dr. Füsun GÖKKAYA, Kıbrıs International University, Faculty of Arts and Sciences, Turkish Republic of Northern Cyprus, e-mail: fusungokkaya@hotmail.com

ORCID: https://orcid.org/0000-0002-9392-0724

Research Assistant Fatih YURDALAN, Kıbrıs International University, Faculty of Arts and Sciences, Turkish Republic of Northern Cyprus, e-mail: yurdalanfatih8@gmail.com

ORCID: https://orcid.org/0000-0002-0498-2342

\begin{abstract}
When the validity and reliability studies of the Self-Compassion Scale were examined in the relevant literature, we did not find a study of the Self-Compassion Scale, which was originally developed for university students and applied by some researchers to adolescents at high school level, with middle school students (12-14 age group). In this context, validity and reliability analyzes were carried out in order to test the suitability of the self-compassion scale for middle school students. The sample consists of a total of 624 secondary school students, 339 girls and 285 boys, aged 12-14. As a data collection tool, the Self-Compassion Scale, which was developed by Neff (2003a) and adapted to Turkish by Akın, Akın and Abacı (2007), was used. It was concluded that the Self-Compassion Scale is a valid and reliable measurement tool for middle school students. It is seen that the obtained fit index values are within acceptable limits and therefore the model has a good fit. At the end of the research, test-retest reliability was calculated as .76 and internal consistency coefficient was calculated as .89. The Self-Compassion Scale was found to be valid and reliable for middle school students.
\end{abstract}

Keywords: Secondary School Students, Self-Compassion, Validity, Reliability.

Received: 30.04 .2021

Accepted: 01.08.2021

Suggested Citation:

Erişen, E., Gökkaya, F. and Yurdalan, F. (2021). Validity and Reliability Study of The SelfCompassion Scale for Secondary School Students Aged 12- 14 Years, Journal of Social, Humanities and Administrative Sciences, 4(8): 730-739.

(C) 2021 Sosyal, Beşerî ve İdari Bilimler Dergisi. 


\section{Gíriş}

Bazı insanlar herhangi bir başarısızlık durumunda yetersizlik hissine kapılırlar. Çoğu zaman yüzeysel bir yaklaşımla bu sınırlılıkları ve yetersizlikleri ile aşırı özdeşim yaparak kendilerine yönelik olumsuz düşünce ve duygular geliştirirler. Başarısız ve yetersiz olmanın tüm insanların yaşayabileceği deneyimlerin bir parçası olabileceğini göz ardı ederler. Tüm bunların sonucunda yalıtılmışlık ve yalnızlık duyguları yaşarlar (Neff ve Vonk, 2009). Öz duyarlığı yüksek olan bireyler ise acı çekmenin ve kusursuz olmanın her insanın yaşamında olan bir durum olduğunu bilir ve bu durumun sadece kendilerine has bir durum olmadığını ve tüm insanların yaşayabileceğini kabul ederler. Öz duyarlılığı yüksek olan birey olumsuz benlik algısı ile duygularına dengeli bir yaklaşım geliştirebilir ve yaşadığı başarısızlıkları, sıkıntıları, yetersizlikleri bastırmaz, yok saymaz, abartmaz ya da dramatize etmez. Dolayısıyla öz duyarlık duygu düzenlemenin bir yolu olarak da görülebilir (Neff, 2003a; Neff, 2003b). Diğer bir deyişle öz duyarlık, bireyin acı, sıkıntı gibi duygularına, ilgiyle ve bilinçli bir şekilde yaklaşabilme becerisidir (Neff ve McGehee, 2010). Öz duyarlık kendine acıma değildir. Çünkü bireyler kendilerine acıdıkları zaman var olan problemlerine gömülürler ve başkalarının da benzer problem yaşadıklarını unuturlar. Böylece sadece kendilerinin bu problemi yaşadığını, acı çeken bir tek kendileri olduklarını düşünerek bir yanılgı içine girerler. Dengeli ve nesnel bir bakış açısı benimseyemezler (Neff ve Dahm, 2015). Öz-duyarlılık kavramının temelini oluşturan "duyarlılık", başkasının duygularına karşı açık olma ve bu duygulardan kaçma yerine onun bu duygularını kabullenmesi için ona yardımcı olma, nazik, şefkatli ve yapılan hatalara karşı önyargısız olarak yaklaşma, herkesin olduğu gibi onun da hatalar yapıp yanılabileceğini göz önüne alabilmedir (Neff ve Vonk, 2009).

Neff (2003a), öz duyarlığın bireyin kendi duygularını keşfetmesinde ve bu duyguları keşfetme sonucunda kendine rehberlik etmesinde oldukça önemli olduğunu belirtmektedir. Öz duyarlığın bu öneminden ve değerlendirecek ölçüm aracının olmamasından dolayı Öz Duyarlık Ölçeğinin geliştirilmesi ihtiyacı doğmuştur. Neff (2003a), Öz Duyarlık Ölçeği orijinal formunu geliştirme sürecinde öncelikle 71 potansiyel ölçek maddesi havuzu oluşturmuştur ve bu ölçek maddelerine yönelik bir pilot çalışma gerçekleştirmiştir. Bu pilot çalışmaya 30 erkek ve 38 kadın olmak üzere 68 üniversite öğrencisi dahil edilmiştir. Yapılan bu pilot çalışmada 68 üniversite öğrencisine öz duyarlıkla ilişkili açık uçlu sorular sorulmuştur. Bu uygulamanın temel amacı ortalama bir kişi tarafından anlaşılacak, bireylerin kendi acı ve başarısızlıklarına yönelik ölçek maddelerini oluşturmaktır (Neff, 2003a). Daha sonra katılımcılara potansiyel ölçek maddeleri sunulmuş ve geri dönüşleri alınmıştır. Pilot uygulamanın ikinci aşamasında potansiyel ölçek maddelerinin uygunluğunu belirleyebilmek için 71 kişi ( 24 erkek ve 47 kadın) daha araştırmaya dahil edilmiştir. Bu 71 kişiye öz tutumlarına yönelik bir ölçek verilmiş ve ölçek yapısının nasıl olduğuna karar verilmiş yani ölçeğin son hali oluşturulmuştur. Bu amaçla ölçeğin iç geçerliğini değerlendirmek için katılımcılara 'Kendilerine ve çevrelerine karşı ne kadar nazik?' olduğu sorulmuştur. Ölçeğin benzer ölçek geçerliğini değerlendirmek için ise katılımcılara öz eleştiri düzeyini ölçen bir ölçek sunulmuştur. Pilot çalışma tamamlanıp ölçek son haline getirildikten sonra ise 391 üniversite öğrencisi (166 erkek 225 kadın) asıl araştırmaya dahil edilmiş ve ölçek maddeleri bu katılımcılara uygulanmıştır. Neff (2003a), bu katılımcıları araştırmaya rastgele bir şekilde seçmiştir. Neff (2003a) tarafından yapılan geçerlik ve güvenirlik analizleri sonucunda ölçeğin 26 maddelik son halinin beşli Likert tipinde olduğu sonucuna ulaşılmıştır. Ayrıca ölçeğin ölçeğin öz-sevecenlik (self-kindness), paylaşımların bilincinde olma (common humanity), farkındalık (mindfulness), izolasyon (isolation), bilinçlilik (self-judgment) ve aşırı özdeşleşme (over-identification) olmak üzere altı alt boyuttan oluştuğu saptanmıştır. Ölçeğin iç tutarlılık güvenirlik katsayısı .92 test-tekrar-test güvenirlik katsayısiise.93'tür. Neff ve diğerleri (2021) bu ölçeği 11-15 yaş arasındaki genç bireyler için de yapmıştır. Bu çalışma sonucunda Öz Duyarlık 
Ölçeği'nin 11-15 yaş arası genç bireyler için güvenilir ve geçerli bir ölçme aracı olduğu sonucuna ulaşılmıştır.

\section{Öz Duyarlık Ölçeğinin Çocuk ve Ergenler için Farklı Ülkelerde Yapılmış Uyarlama Çalışmaları}

Öz Duyarlık Ölçeğine ilişkin çalışmalar birçok ülkede çeşitli yaş grupları için gerçekleştirilmektedir. Çocuk ve ergenler için yapılan uyarlama çalışmalardan bazıları aşağıda sunulmaktadır:

\section{Amerika'da Yapılan Çalışma}

Neff ve diğerlerinin (2021) yapmış olduğu araştırmada yaşları 11-15 arasında değişen 279 Amerikalı ergen örneklem grubu olarak kullanılmıştır ve Öz-Duyarlılık Ölçeğinin bu grup için geçerlik ve güvenirliği incelenmiştir. Bu araştırmada elde edilen sonuçlara göre, kurulan modelin uyum indeksleri kabul edilebilir sınırlar içinde olduğu, iç geçerliliğin sağlandığı ve Cronbach alfa değerinin .74 ile .80 arasında değiştiği bulunmuştur.

\section{Kanada'da Yapılan Çalışma}

Sutton ve diğerlerinin (2018) yaptığı araştırmada bu ölçeğin geçerlik ve güvenirlik çalışmasını yaş grubu 8-12 arasında olan 406 Kanadalı çocuk ile gerçekleştirmiştir. Bu araştırmadan elde edilen sonuca göre, test tekrar test güvenirlik korelasyon katsayısının .85 ile .93 ve iç tutarlılık katsayısının .75 ile .81 arasında değişmektedir.

\section{Portekiz'de Yapılan Çalışma}

Cunha ve diğerlerinin (2016) yaptığı araştırmada Öz-Duyarlılık Ölçeğinin geçerlik ve güvenirlik çalışması yaş grubu 12-19 arasında olan 3165 Portekizli ergen ile yapılmıştır. Bu araştırmanın sonuçlarına göre kurulan model iyi uyum göstermiş, yeterli düzeyde iç geçerliliğe (Cronbach alfa= .92) ve yapı geçerliğine sahip olduğu saptanmıştır.

\section{Çin'de Yapılan Çalışma}

Zhou ve diğerlerinin (2019) yaptığı araştırmasında Öz-Duyarlık Ölçeğinin geçerlik ve güvenirlik çalışması 9-12 yaş aralığında olan Çinli çocuklar için yapılmıştır. Bu çalışma sonucunda ÖzDuyarlılık Ölçeğinin 9-12 yaş grubunda olan hem erkek hem kız çocukları için geçerli ve güvenilir olduğu bulunmuştur. Araştırmada ölçeğin alt boyutları için Cronbach alfa değerinin .66 ile .85 arasında değiştiği ve yapılan doğrulayıcı faktör analizi sonucunda uyum indekslerinin kabul edilebilir sınırlar içinde olduğu sonucuna ulaşılmıştır.

\section{Hollanda'da Yapılan Çalışma}

Muris ve diğerlerinin (2016) yaptığı araştırmada ise Hollandalı ve yaş grubu 12-17 arasında değişen ergen grup için Öz-Duyarlık Ölçeğinin geçerlik ve güvenirlik çalışması yapılmıştır. Bu araştırma sonucunda Cronbach alfa değeri .84 olarak hesaplanmıştır. Ayrıca yapılan faktör analizi sonucunda varyansın \%71,44'ünün açıklandığı belirtilmiştir. 


\section{Türkiye'de Yapılan Çalışma}

Ölçeğin Türkçe'ye uyarlama çalışması Akın, Akın ve Abacı (2007) tarafından yapılmıştır. Akın, Akın ve Abacı (2007) tarafından yapılan geçerlik ve güvenirlik çalışmalarıSakarya Üniversitesi Eğitim Fakültesi'nde öğrenim gören 633 üniversite öğrencisi ile gerçekleştirilmiş ve ölçeğin dilsel eşdeğerliliği incelenmiştir. Dilsel eşdeğerliliğe sahip olduğu görüldükten sonra geçerlik ve güvenirlik analizleri yapılmıştır. Yapılan doğrulayıcı Faktör Analizinde ölçeğin orijinal formuyla uyumlu sonuçlara ulaşıldığ 1 saptanmıştır $\left(x^{2}=779.01\right.$, $\mathrm{sd}=264, p=0.00$, RMSEA $=.056$, NFI $=.95, \mathrm{CFI}=$ $.97, \mathrm{IFI}=.97, \mathrm{RFI}=.94, \mathrm{GFI}=.91$ ve SRMR= .059). Ölçeğin iç tutarlık katsayıları sırasıyla .72 ile .80 ve test-tekrar-test güvenirliği katsayıları ise sırasıyla .56 ile .69 olarak bulunmuştur. Ayrıca ölçeğin düzeltilmiş madde toplam korelâsyonlarının .48 ile .71 arasında olduğu ve \%27'lik alt üst grupların ortalamaları arasındaki tüm farkların anlamlı olduğu bulunmuştur. Bu sonuçlar Türkçe formunun da öz-duyarlılık ölçeğinin geçerli ve güvenilir bir ölçme aracı olduğunu göstermektedir (Akın, Akın ve Abacı, 2007).

\section{Çalışmanın Önemi}

Öz-Duyarlık Ölçeğinin geçerlik ve güvenirlik çalışmaları ilgili literatür incelendiğinde, orijinali üniversite öğrencileri için geliştirilmiş olan (Neff, 2003b) ve bazı araştırmacıların lise düzeyinde ergenlere uyguladığ1 (Akkaya, 2011; Neff ve McGehee, 2010; Toksoy, 2018) ülkemizde özduyarlık ölçeğinin ortaokul öğrencileri yaş grubu ile yapılan bir geçerlik-güvenirlik çalışmasına rastlanmamıştır. Öz duyarlığın bireyin kendi duygularını erken yaşta keşfetmesindeki önemi düşünüldügünde bu araştırmanın yapılmasına karar verilmiştir. Bu kapsamda öz-duyarlık ölçeğinin, ortaokul öğrencileri için uygunluğunu test etmek amacıyla geçerlik ve güvenirlik analizleri yapılmıştır. Araştırma grubu için oluşan yapıya ilişkin gerçekleştirilen birinci düzey doğrulayıcı faktör analizinde model üzerinde hiçbir modifikasyon gerçekleştirmeden ulaşılan Path diyagramı Şekil 1'de; uyum iyiliği indeksleri ise Tablo 1'de gösterilmiştir.

\section{YÖNTEM}

\section{Örneklem}

Araştırma, İzmir İli Karşıyaka İlçe Merkezinde bulunan 2 ortaokula devam eden 7. ve 8. sınıf öğrencileri ile yürütülmüştür. Örneklem, 12-14 yaş aralığında olan 339 kız ve 285 erkek toplam 624 ortaokul öğrencisinden oluşmaktadır.

\section{Veri Toplama Araci}

Öz-DuyarlıkÖlçeği Neff (2003a) tarafından geliştirilmiş, Türkçe uyarlama çalışması ise Akın, Akın ve Abacı (2007) tarafından gerçekleştirilmiştir. 26 maddeden oluşanölçek (1) hiçbir zaman, (2) nadiren, (3) sık sık, (4) genellikle ve (5) her zamanşeklinde derecelendirilmiş 5'li Likert tipi bir ölçektir. Ölçek Öz-Sevecenlik (2, 6, 13, 17, 21), Öz-Yargılama $(4,7,15,20$, 26), Paylaşımların Bilincinde Olma (1, 8, 12, 22), İzolasyon (5, 11, 19, 25), Bilinçlilik $(9,14,18,23)$ ve Aşırı Özdeşleşme $(3,10,16,24)$ alt ölçeklerinden oluşmaktadır. Uyarlama çalışmasında ölçeğin güvenirlik katsayısı 0.93; Cronbach Alfa değeri ise 0.73 olarak bulunmuştur.

\section{İşlem}

Araştırmaya Yakın Doğu Üniversitesi'nden etik kurul izni alınarak başlanmıştır. Daha sonra İl Milli Eğitim Müdürlüğü'nden izin alınmıştır. Öz-Duyarlık Ölçeğinin öğrencilere uygulanması 
araştırmacı tarafından bireysel olarak yapılmıştır. Uygulamalar ders saatleri içinde uygun zamanlarda yapılmıştır. Uygulamaya başlamadan önce araştırmacı tarafından katılımcılara bilgilendirilmiş bir onam sunulmuş, araştırmanın amacı açıklanmış ve gönüllülük esas olduğu belirtilmiştir.

\section{Geçerlik ve Güvenirlik Çalışmaları}

Geçerlik ve güvenirlik çalışmalarıyla ilgili literarür incelendiğinde, orjinali üniversite öğrencileri için geliştirilmiş olan (Neff, 2003b) ve bazı araştırmacıların lise düzeyinde ergenlere uyguladığ 1 (Akkaya, 2011; Neff ve McGehee, 2010; Toksoy, 2018), Öz Duyarlık Ölçeğinin ortaokul öğrencileri için geçerlik güvenirlik için bir çalışmaya rastlanmamıştır. Bu kapsamda Öz-duyarlık ölçeğinin, ortaokul öğrencileri için yapı geçerliğini test etmek amacıyla Doğrulayıcı Faktör Analizi (DFA) yapılmıştır. Araştırma grubu için oluşan yapıya ilişkin gerçekleştirilen birinci düzey doğrulayıcı faktör analizinde model üzerinde hiçbir modifikasyon yapılmadan yol analizi gerçekleştirilmiştir. Ölçeğin toplam puan verip veremeyeceğinin belirlenmesi için ise ikinci düzey DFA gerçekleştirilmiştir.

\section{BULGULAR}

\section{Geçerlik Analizi}

12-14 yaş grubu için Öz Duyarlık Ölçeğinin geçerliğini belirlemede Doğrulayıcı Faktör Analizi kullanılmıştır. DFA, faktörler arasında ilişki olup olmadığını, değişkenlerin hangi faktörlerle ilişkili olduğunu ve faktörlerin modelin açılaması için yeterli olup olmadığını değerlendirir (Erkorkmaz vd., 2013). Yapılan birinci düzey doğrulayıcı faktör analizi sonucunda modelin kabul edilebilir bir uyum iyiliğine sahip olduğu bulunmuştur. Birinci düzey doğrulayıcı faktör analizine ilişkin bulgular Tablo 1'de görülmektedir.

Tablo 1. Birinci Düzey Doğrulayıcı Faktör Analizi İçin Uyum İndeksleri

\begin{tabular}{lllllll}
\hline$\chi 2$ & $D f$ & $P$ & $\chi 2 / d f$ & GFI & CFI & RMSEA \\
671.136 & 284 & .000 & 2.363 & .92 & .92 & .04 \\
\hline
\end{tabular}

$[\chi 2 / \mathrm{df}=2.363(p=.000) ; \mathrm{RMSEA}=.047 ; \mathrm{GFI}=.922 ; \mathrm{AGFI}=.904 ; \mathrm{CFI}=.926 ;$

$\mathrm{NFI}=.879 ; \mathrm{SRMR}=.0507]$.

Modelin uyum iyiliği indeksleri incelendiğinde, $x^{2} / d f$ değerinin 2.36 olduğu görülmektedir. Bu değerin 3 veya altında bir değer olması modelin iyi bir model olduğunu 5 veya daha altında değer olması ise modelin kabul edilebilirbir uyum iyiliğine sahip olduğunu gösterirken; GFI, CFI ve AGFI değerlerinin .90'ın üzerinde olması modelin iyi uyum gösterdiğinin bir diğer göstergesi olarak ele alınabilir (Schermelleh-Engel vd., 2003).

Öz-duyarlık ölçeğinin alt boyutları arasındaki kovaryans ilişkiler ise path diyagramından anlaşıldığı üzere kuramsal literatürle oldukça uyumludur ve kovaryans analizi için tüm ilişkiler anlamlıdır. Tüm bu analiz sonuçları incelendiğinde öz-duyarlık ölçeğinin bu örneklem grubu için birinci düzey DFA'sının doğrulandığı söylenebilir. Bu doğrultuda ölçeğin toplam puan verip veremeyeceğinin belirlenmesi için ikinci düzey DFA analizigerçekleştirilmiştir.

$\mathrm{Bu}$ çalışmanın örneklem grubu için, oluşan yapıya ilişkin gerçekleştirilen ikinci düzey doğrulayıcı faktör analizinde model üzerinde hiçbir modifikasyon gerçekleştirmeden ulaşılan Path diyagramı Şekil 2'de, uyum iyiliği indeksleri ise Tablo 2' de gösterilmiştir. 


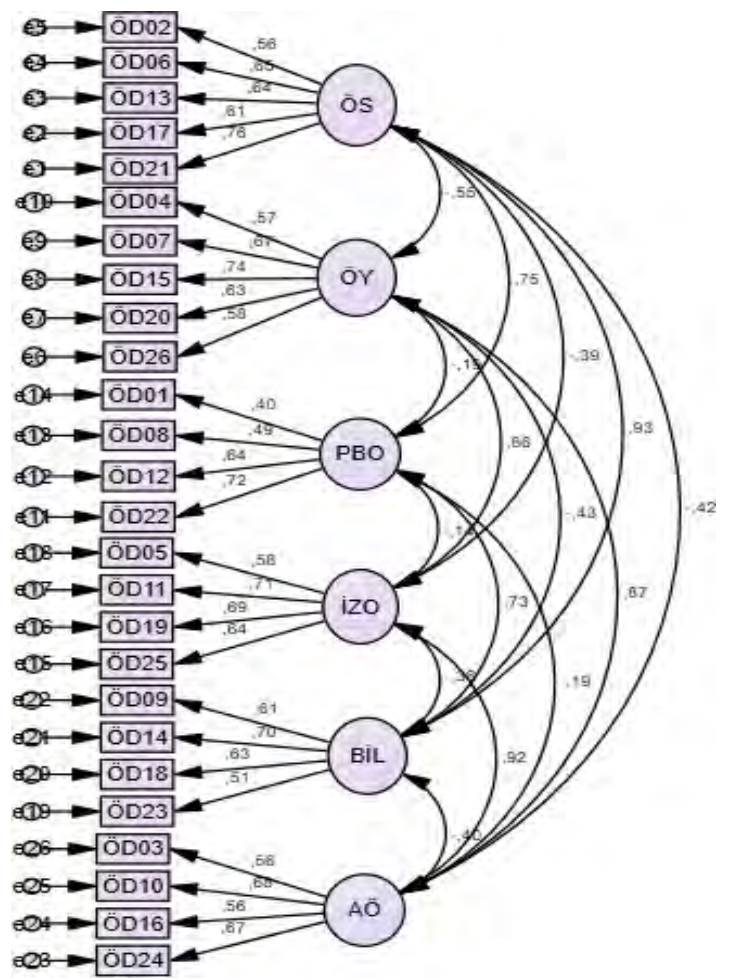

Şekil 1. Öz-Duyarlık Ölçeği Birinci Düzey DFA Sonuçları

Tablo 2. İkinci Düzey Doğrulayııı Faktör Analizi için Uyum İndeksleri

\begin{tabular}{lllllll}
\hline$\chi 2$ & $D f$ & $P$ & $\chi 2 / d f$ & GFI & CFI & RMSEA \\
1263.597 & 293 & .000 & 4.313 & .85 & .81 & .07 \\
\hline
\end{tabular}

$[\chi 2 / \mathrm{df}=4,313(p=.000) ; \mathrm{RMSEA}=.073 ; \mathrm{GFI}=.857 ; \mathrm{AGFI}=.829 ; \mathrm{CFI}=.814 ; \mathrm{NFI}=.772 ;$ $\mathrm{SRMR}=.10]$.

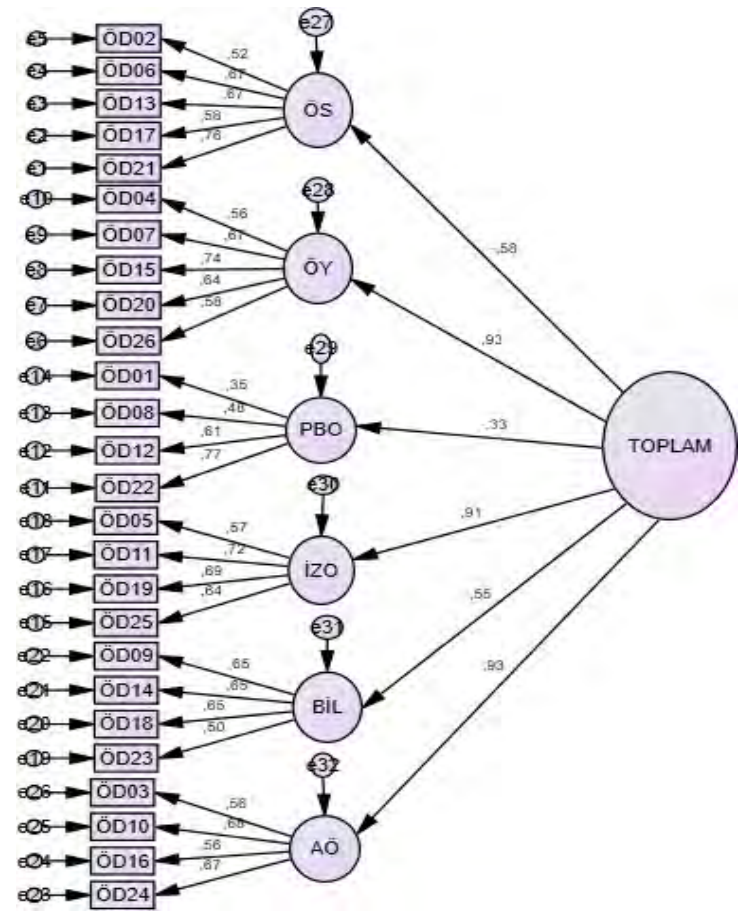

Şekil 2. Öz-Duyarlık Ölçeği İkinci Düzey DFA Sonuçları 
Modelin uyum iyiliği indeksleri incelendiğinde, $\chi 2 / \mathrm{df}$ değerinin 4.313 olduğu görülmektedir. Bu değerinin 3 veya altında bir değer olması modelin iyi bir model olduğunu 5 veya daha altında bir değer alması ise modelin kabul edilebilir bir uyum iyiliğine sahip olduğunu gösterirken; GFI, CFI ve AGFI değerlerinin .90'ın altında olması sınırda uyum gösterdiğinin bir diğer göstergesi olarak ele alınabilir (Schermelleh-Engel, Moosbrugger ve Müller, 2003). RMSEA değerinin .80'in altında olması kabul edilebilir uyuma sahip olduğunu gösterirken; diğer değerler birinci düzey DFA sonuçlarına göredaha düşük olsa da sınırda uyum göstergesi içerisinde ele alınabilir.

Tüm bu geçerlik çalışmaları doğrultusunda, orijinali üniversite öğrencilerinde geliştirilmiş olan (Akın, Akın ve Abacı, 2007); ancak lise düzeyinde bazı araştırmacılar (Akkaya, 2011; Neff ve McGehee, 2010; Toksoy, 2018) tarafından uygulanan öz-duyarlık ölçeğinin bu araştırma grubu (12-14 yaş) içinde geçerli sonuçlar verdiği söylenebilir.

\section{Güvenirlik Analizi}

$\mathrm{Bu}$ araştırma grubu için ayrıca öz- duyarlık ölçeğinin alt boyutları ve toplam puanları arasındaki güvenirlik analizleri için iç tutarlılık katsayıları olan $\mathrm{Cr} \alpha$ katsayıları hesaplanmış ve Tablo 3 'te verilmiştir. Ölçeğin güvenirliğini belirlemek amacıyla test tekrar test yöntemi uygulanmıştır.

Tablo 3. Öz-Duyarlık Ölçeği Alt Boyut ve Toplam Puan İç Tutarlılık Katsayıları

\begin{tabular}{lcc}
\hline Alt Boyutlar: & Madde Sayısı & Cr $\alpha$ \\
\hline Öz-sevecenlik & 5 & .78 \\
Öz-yargılama & 5 & .77 \\
Paylaşımların Bilincinde Olma & 4 & .64 \\
İzolasyon & 4 & .74 \\
Bilinçlilik & 4 & .70 \\
Aşı̈ı özdeşleşme & 4 & .71 \\
\hline Öz-Duyarlık Toplam Puanı: & 26 & .89 \\
\hline
\end{tabular}

Güvenirlik katsayılarının .70'in üzerinde olması ölçme aracının güvenirlik düzeyinin yeterli olduğunun bir göstergesidir. Öz-Duyarlık Ölçeğinin hem alt boyut hem de toplam puan açısından bu araştırma grubu için güvenilir sonuçlar verdiği söylenebilir. Tablo 3'te görüldüğü üzere Öz-Duyarlık Ölçeğinin toplam puanından elde edilen güvenirlik katsayısı ( $\mathrm{Cr} \alpha=.89)$, alt boyutların güvenirlik katsayılarından nispeten yüksek olduğu için bu çalışmada öz-duyarlık kavramı toplam puan olarak ele alınmış ve analizler toplam puan üzerinden gerçekleştirilmiştir. Ölçeğin ortaokul öğrencileri grubunda güvenirliğini ölçmek amacıyla test-tekrar test yöntemi kullanılmıştır. Test-tekrar test güvenilirliğini incelemek için Öz-Duyarlılık Ölçeği 8. sınıflardan toplam 40 öğrenciye bir ay ara ile uygulanmıştır. İki ölçüm arasındaki korelasyon analiz sonucunda test-tekrar test güvenilirliğinin $\mathrm{r}=0.76$, $(\mathrm{p}<0.05)$ olduğu bulunmuştur.

\section{TARTIŞMA, SONUÇ ve ÖNERILLER}

$\mathrm{Bu}$ araştırmanın amacını gerçekleştirmek için, Neff (2003b) tarafından geliştirilen ve Türkçe'ye uyarlama çalışması Akın, Akın ve Abacı (2007) tarafından gerçekleştirilen Öz Duyarlık Ölçeğinin ortaokul öğrencileri (12-14 yaş grubu) için geçerlik ve güvenirlik çalışması yapılmıştır. Öz Duyarlık Ölçeğinin geçerliğini saptamak için yapılan birinci düzey doğrulayıcı faktör analizi sonucunda modelin iyi uyum gösterdiği, kovaryans 
analizi için tüm ilişkiler anlamlı ve ölçeğin alt boyutları arasındaki kovaryans ilişkilerin kuramsal literatürle oldukça uyumlu olduğu bulunmuştur (Hollis-Walker ve Colosimo, 2011; Neff, 2016; Zessin vd., 2017). Gerçekleştirilen ikinci düzey doğrulayıcı faktör analizi sonucunda ise uyum iyiliği değerlerinin sınırda uyum gösterdiği sonucuna ulaşılmıştır. Ölçeğin güvenirlik sonuçlarını değerlendirmek için ise test tekrar test yöntemi uygulanmış ve iç tutarlılık katsayı değeri .76 olarak saptanmıştır. Bu iç tutarlılık katsayı değeri ölçeğin güvenilir bir şekilde kullanılabileceğine işaret etmektedir ve literatürdeki diğer sonuçlarla bu bağlamda benzerlik göstermektedir (Stolow vd., 2016; Cunha vd., 2016; Sutton vd., 2018).

Gerçekleştirilen tüm geçerlik ve güvenirlik analizleri sonucunda, yapılan çalışmada ÖzDuyarlılık Ölçeğinin ortaokul öğrencileri için geçerli ve güvenilir bir yapısının olduğu bulunmuştur. Neff ve McGehee'nin (2010) belirttiği üzere öz duyarlık bireyin gelişimi için oldukça önemlidir. Fakat öz duyarlık üzerine yapılan araştırmaların çoğu yetişkin popülasyonlara yöneliktir ve çocuklara ya da ergenlere yönelik çalışmalar nadirdir. Bununla birlikte, literatürde farklı ülkelerde yapılan bazı çalışmaların araştırmanın örneklem grubuyla ve bulgularıyla benzer sonuçlar rapor ettiği görülmüştür.

Bu çalışma, Öz-Duyarlık Ölçeğinin ortaokul öğrencileri (12-14 yaş) örnekleminde öz duyarlık yapısını, psikometrik özelliklerini, boyutsal yapısını ve ölçüm değişmezliği saptamıştır. Buna ek olarak, birinci ve ikinci düzey faktör analizinden elde edilen sonuçlar hem altı faktörlü hem de ikinci dereceden modellerin verilere iyi bir uyum gösterdiğini desteklemektedir. Yurt dişında yapılan tüm bu araştırmalarda yapılan çalışmada olduğu gibi (Muris vd., 2016; Cunha vd., 2016; Sutton vd., 2018; Zhou vd., 2019 Neff vd., 2021) Öz-Duyarlık Ölçeğinin 6 alt boyutu olduğu saptanmıştır. Dolayısıyla yapılan bu çalışmanın literatürde bulunan diğer araştırma bulgularıyla benzer sonuçlar gösterdiği ve literatür tarafından desteklendiği söylenebilir. Elde edilen bu bulgular, öz duyarlılığın kuramsal kavramsallaştırması ile (Neff, 2003a) uyumlu olduğu şeklinde değerlendirilebilir.

\section{KAYNAKÇA}

Akın, Ü., Akın, A., and Abacı, R. (2007). Self-compassion scale: The study of validity and reliability. Hacettepe University Journal of Education, 33, 1-10.

Akkaya, Ç. (2011). Ortaöğretim öğrencilerinde algılanan sosyal destek ve öz-duyarlık düzeyleri. Yüksek Lisans Tezi, Eğitim Bilimleri, Eğitimde Psikolojik Hizmetler, Konya.

Cunha, M., Xavier, A., and Castilho, P. (2016). Understanding self-compassion in adolescents: Validation study of the Self-Compassion Scale. Personality and Individual Differences, 93, 56-62.

Erkorkmaz, Ü., Etikan, İ., Demir, O., Özdamar, K., ve Sanisoğlu, S. Y. (2013). Doğrulayıcı faktör analizi ve uyum indeksleri. Turkiye Klinikleri Journal of Medical Sciences, 33(1), 210-223.

Hollis-Walker, L., and Colosimo, K. (2011). Mindfulness, self-compassion, and happiness in nonmeditators: A theoretical and empirical examination. Personality and Individual Differences, 50(2), 222-227.

Muris, P., Meesters, C., Pierik, A., and de Kock, B. (2016). Good for the self: Self-compassion and other self-related constructs in relation to symptoms of anxiety and depression in non-clinical youths. Journal of Child and Family Studies, 25(2), 607-617. 
Neff, K. D. (2003a). The development and validation of a scale to measure self-compassion. Self and identity, 2(3), 223-250.

Neff, K. D. (2003b). Self-compassion: An alternative conceptualization of a health attitude toward oneself. Self and Identity, 2(2), 85-101.

Neff, K. D., Bluth, K., Tóth-Király, I., Davidson, O., Knox, M. C., Williamson, Z. and Costigan, A. (2021). Development and validation of the Self-Compassion Scale for Youth. Journal of Personality Assessment, 103(1), 92-105.

Neff K. D. and Dahm K. A. (2015). Self-compassion: What it is, what it does, and how it relates to mindfulness. In Handbook of Mindfulness and Self-regulation (pp.121-137). Springer, New York, NY.

Neff, K. D. and McGehee, P. (2010). Self-compassion and psychological resilience among adolescents and young adults. Self and Identity, 9(3), 225-240.

Neff, K. D. and Vonk, R. (2009). Self-compassion versus global self-esteem: Two different ways of relating to oneself. Journal of Personality, 77(1), 23-50.

Schermelleh-Engel, K., Moosbrugger, H., and Müller, H. (2003). Evaluating the fit of structural equation models: Tests of significance and descriptive goodness-of-fit measures. Methods of Psychological Research Online, 8(2), 23-74.

Stolow, D., Zuroff, D. C., Young, J. F., Karlin, R. A., and Abela, J. R. (2016). A prospective examination of self-compassion as a predictor of depressive symptoms in children and adolescents. Journal of Social and Clinical Psychology, 35(1), 1-20.

Sutton, E., Schonert-Reichl, K. A., Wu, A. D. and Lawlor, M. S. (2018). Evaluating the reliability and validity of the self-compassion scale short form adapted for children ages 8-12. Child Indicators Research, 11(4), 1217-1236.

Toksoy, P. (2018). Ergenlerde kendine zarar verme davranışının yordayıcıları olarak öz duyarlık ve stresle başa çıkma tarzları. (Yüksek lisans tezi, Karadeniz Teknik Üniversitesi, Eğitim Bilimleri Enstitüsü, Trabzon).

Zessin, U., Dickhäuser, O., and Garbade, S. (2015). The relationship between self-compassion and well-being: A meta-analysis. Applied Psychology: Health and Well-Being, 7(3), 340-364.

Zhou, H., Wang, Y., Ding, J., Wang, Y., and Pan, J. (2019). Development and validation of an AgeAppropriate Self-Compassionate Reactions Scale for Children (SCRS-C). Mindfulness, 10(11), 2439-2451. 